\title{
Entretenimento, a utopia e 0 discurso mitigado
}

\author{
Jacques Alkalai Wainberg
}

\section{Resumo}

Este estudo teórico elabora sobre o papel desempenhado pelo entretenimento na consolidação de um imaginário utópico. Examina o papel do discurso metafórico utilizado nas alegorias míticas e noutros bens simbólicos, como os produzidos pela cinematografia e pelas telenovelas. Distingue entre as utopias existenciais e as vivenciais e mostra a relevância da sutileza das mensagens da indústria do passatempo na consolidação das motivações políticas das pessoas.

\section{Palavras-Chave}

Utopia. Discurso. Entretenimento. Metáfora. Persuasão.
Jacques Alkalai Wainberg | jacqalwa@pucrs.br Doutor em Ciências da Comunicação pela Universidade de São Paulo Pós-doutorado por meio da Universidade de Tel Aviv - Israel e Universidade do Texas - EUA. Professor titular da Pontifícia Universidade Católica do Rio Grande do Sul - PUCRS.
A utopia permite à pessoa escapar da realidade.

Este mesmo tipo de efeito é produzido pelo entretenimento. Em ambos, predominam a fantasia e a imaginação. Mas, ao contrário das experiências lúdicas proporcionadas pelos filmes e pelas telenovelas, por exemplo, as utopias políticas e religiosas são pretensiosas. Elas se enroscam nas mazelas sociais e na dor do mundo. Seu labor educativo se diferencia por este aspecto militante. Se falasse, a utopia, certamente, responderia com furor à acusação de que ela é parceira do mercado das ilusões. Ambos inebriam os espíritos, é verdade, muito embora a missão diversional da mídia não se proponha à rebelião dos sentidos. Pedimos para ser enganados, diz Hedges (2009, p. 5). Há um traço conservador no happy end, nos heróis e nas tramas ficcionais produzidas para afagar o humor coletivo. Os produtores culturais parecem querer manipular a atenção da audiência e proporcionar ao público algum desfrute, algo que ocorre, por exemplo, com os telespectadores.

Estudo sobre os hábitos de consumo da televisão de Brock \& Livingston (2004) mostra que as pessoas distraídas pela TV ficam relaxadas e passivas. 
Mesmo após desligarem os aparelhos, elas relatam que esses efeitos continuam por algum tempo. É como se a TV tivesse sugado da audiência sua energia vital. Com frequência, os espectadores acabam também assistindo TV mais tempo do que eles pretendiam, apesar de sua programação não ser recompensadora. Isso também acontece no cinema, onde poucos assistentes abandonam a sala quando o filme lhes desagrada. Em ambos os casos, a maior parte das pessoas simplesmente se deixa levar pelas imagens e pelos sons da tela.

Portanto, a passividade causada no comportamento do público parece ser uma propriedade do entretenimento. Apesar deste efeito amortecedor, há que se pensar na contribuição que os produtos de aparência inocente da indústria cultural são capazes de oferecer à imaginação política das pessoas. Segundo Dyer,

0 entretenimento oferece a imagem de 'algo melhor' para se escapar, ou algo que nós desejamos profundamente e que nosso dia-a-dia não oferece. Alternativas, esperanças, desejos estes são os elementos da utopia, a sensação de que as coisas podem ser melhores, que algo distinto do que é pode ser imaginado e pode ser realizado (Dyer, 2002, p.20).

\section{Simulacro}

A fina camada que separa o real da ilusão é facilmente transposta pelo público. Por consequência, ao serem tocadas pela imaginação,

\section{Figura 1: Primeira representação do Golem}

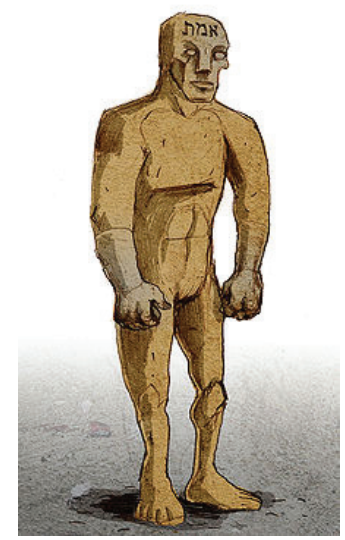

Fonte: clicar na imagem.

as pessoas tornam-se sonâmbulas. Elas sonham acordadas. As imagens que passam a circular em suas mentes foram nominadas de simulacro. Trata-se da cópia de algo que nunca existiu de fato. Conforme Jean Baudrillard, o simulacro é a experiência de algo que simula a realidade. Este autor propõe a existência de quatro tipos de imagens: a que reflete a realidade; a que a perverte; a que a falsifica e 0 simulacro que não tem relação direta com ela (Baudrillard, 1991).

Exemplo de simulacro é o Golem (Figura 1), uma figura concebida e criada pelo ser humano, e que recebe de forma misteriosa o sopro da vida. Esta fantasia mística judaica é antiga (o termo apareceu uma única vez na Bíblia, em Salmos 139:16 $)$. Ela se disseminou na Idade Média passando a significar uma pessoa tola, que age como se fosse um robô (Trachtenberg, 2012; p. 67). 
Figura 2: As versões modernas do Golem
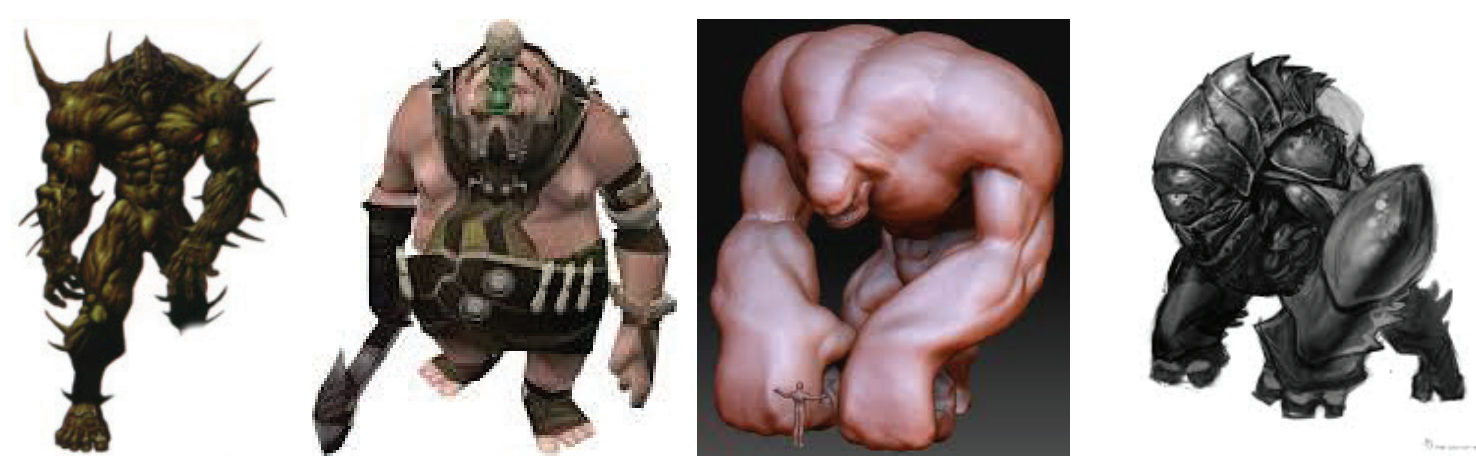

Fonte: clicar na imagem.

0 Golem é referido também no Talmud para

descrever a fase em que Adão, feito do pó da

terra, ainda não havia assumido a forma humana

definitiva (Sanedrim, 38b). Conta-se que no

século XVI o rabino Iehuda de Praga (1520-1609)

criou um Golem que lhe serviu de servo e que

também salvou os judeus da perseguição, a que

surgiu em decorrência da falsa acusação de que

estavam envolvidos em assassinatos rituais. ${ }^{2} \mathrm{Na}$

testa do Golem estava inscrita a palavra hebraica

EMET (Verdade). A destruição desta criatura

poderia ser obtida retirando a primeira letra do

verbete. Restaria então MET (Morte). Assim,

baseando-se nessa parábola, o rabino Jacob

ben Shalom (viveu no século XIV na Alemanha e

depois em Barcelona) diz que a lei da destruição nada mais é do que o inverso da lei da criação

(Trachtenberg, 2012; p. 68).

Eu Robô, obra de Isaac Azimov (2005), remete

ao mesmo motivo do temor de que 0 Golem possa eventualmente se voltar contra o seu criador.

0 Golem, de Isaac Azimov, é um serviçal que se rebela devido a um erro de programação que provê ao Robô o livre-arbítrio. A solução encontrada pelo movimento ludita a esse mesmo dilema da autonomia das máquinas foi atacar e destruir as fábricas durante a Revolução Industrial. Reação similar é sugerida agora pelo anarcoprimitivismo, um movimento que propõe a recusa da vida moderna e um retorno a formas sociais primitivas através da desindustrialização,

Este seria o tema do filme alemão Der Golem, wie er in die Welt kam (0 Golem: Como Veio ao Mundo). Sua estreia ocorreu em 1920 e seria apresentado ao público somente três vezes. Nos círculos cabalistas, o livro Sefer Yetzirah é mencionado como contendo o método secreto para se criar um Golem. Esta figura foi igualmente utilizada na discussão contemporânea sobre se é possível os crentes completarem o miniam (o grupo de 10 homens necessários à realização de uma prece comunitária) com a participação virtual, através do Skype, por exemplo, de uma décima pessoa. No passado, a pergunta era se 0 Golem poderia ser esta décima pessoa. Rav Tzvi Ashekenazi (conhecido por Chacham Tzvi, ou o Sábio Tzvi) negou a participação do Golem no miniam. Esta responsa foi a fonte utilizada pelos exegetas contemporâneos para negar a participação de uma imagem gerada por computador no miniam.

Ver em: https://www.youtube.com/watch?v=BqZHc2uak1s; ver em: https://www.youtube.com/watch?v=kEfgYHz7Rbc 
Figura 3: Diferentes formas de representação do Golem

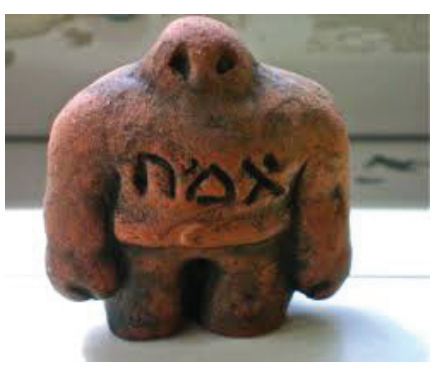

Versão infantil do Golem

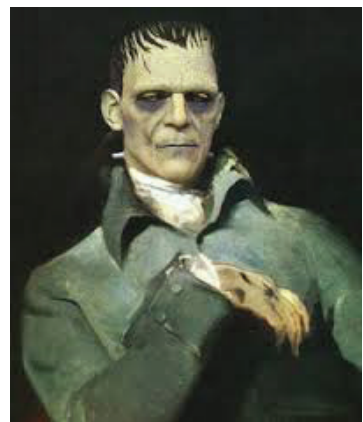

Frankenstein

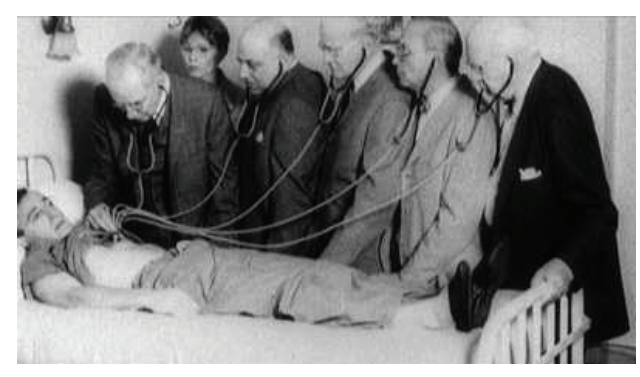

Zelig, o Golem de Woody Allen

Fonte: clicar na imagem.

da abolição da divisão do trabalho e do abandono da tecnologia moderna, como proposto pelo filósofo John Zerzan e por grupos associados, entre eles 0 anarquismo verde (divulgado por pensadores como Élisée Reclus, Piotr Kropotkin e Murray Bookchin), e a tendência anarquia pósesquerda (divulgado por Hakim Bey, pseudônimo de Peter Lamborn Wilson).

Já 0 ‘Golem espantalho’ é utilizado na festa de Halloween para proteger os lares. 0 Golem judaico influenciou também a novelista Mary Shelley a criar sua novela Frankenstein, publicada em 1818 (Figura 3). Woody Allen apresenta em Zelig, através deste personagem camaleão, sua versão cinematográfica do Golem (Figura 3).

Tomar a ilusão por realidade é usual às crianças até os sete anos de idade, aproximadamente. Elas têm amigos imaginários e brincam com seus brinquedos como se eles tivessem uma alma, como se fossem Golens em miniaturas (Figura 3), algo que ocorre também com suas criações feitas de massinha de modelar (Figura 4).

Seres artificiais similares como os androides e os personagens de Toy Story e Pinóquio (Figura 5), que são animados com o sopro da vida; as caricaturas; os mundos artificiais como os propostos nos filmes O Show de Truman e Uma Noite no Museu e nos reality shows da televisão; espaço como o Jurassic Park; cidades típicas reconstituídas, como é o caso de Williamsburg, localizada próxima a Washington, e os parques temáticos, como a Disneylândia, se enquadram no conceito de simulacro.

Outro exemplo ainda é o trompe l'oeil, 'o engana o olho' (Figura 6), técnica artística que cria uma ilusão ótica. Foi utilizada, por exemplo, nos murais das ruas de Pompéia. 
Figura 4: Relações modernas com o Golem

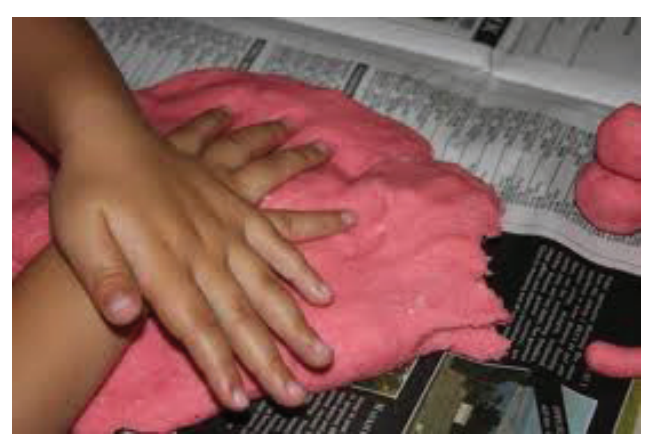

A manipulação infantil da argila

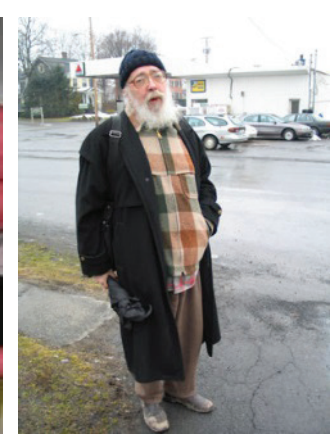

Hakim Bey

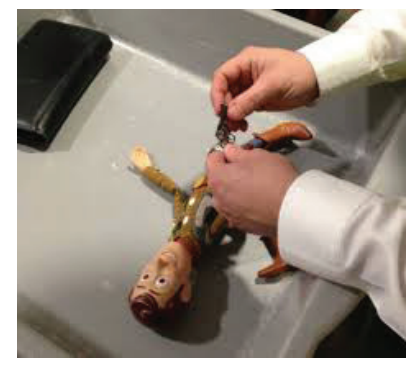

0 boneco Woody de Toy Story

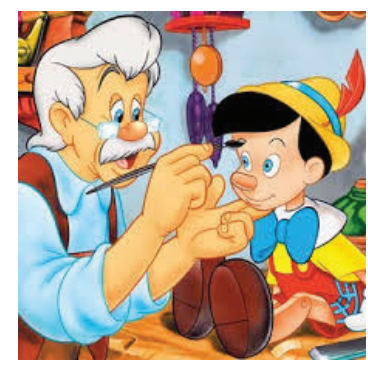

Pinóquio

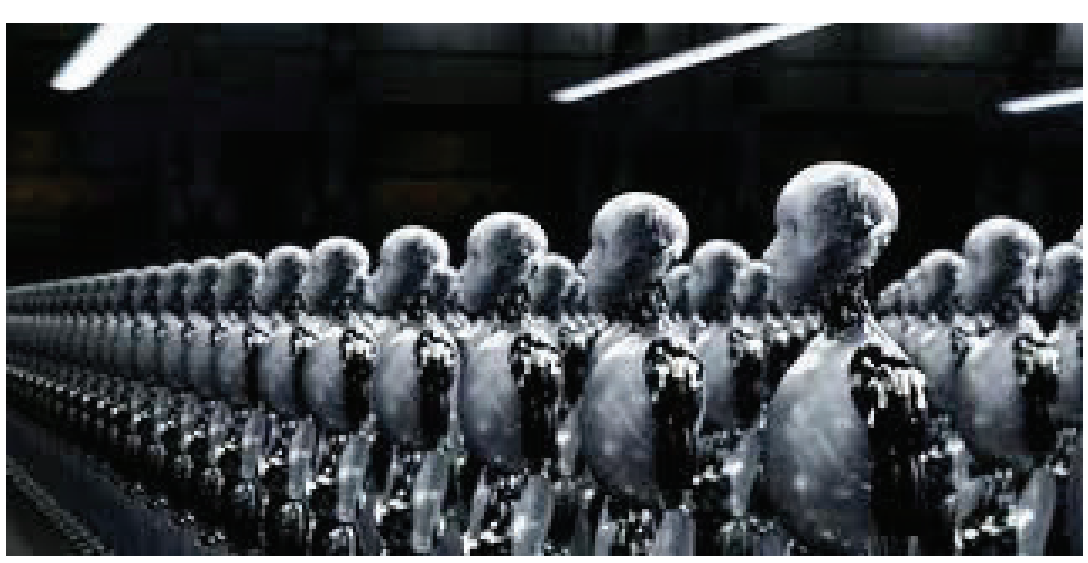

O Robô, de Isaac Azimov 
Figura 6: Técnica artística do "engana olho"

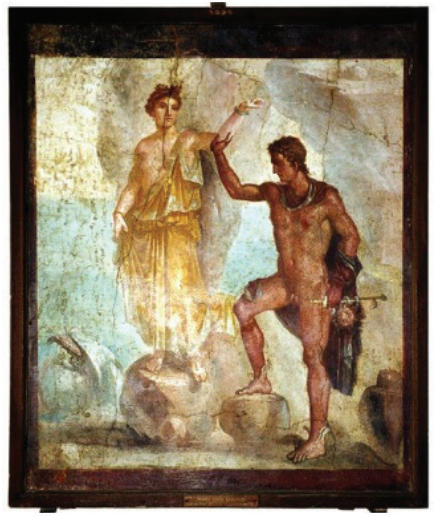

Fonte: clicar na imagem.

A programação da televisão oferece outros inúmeros exemplos de simulacros. Cabe lembrar, a propósito, que a telenovela não é 0 espelho do mundo e que os teledramas não são o mapa de um território. Por isso mesmo é que o mundo virtual povoado por este tipo de narrativa é denominado por muitos autores de hiper-real (Baudrillard, 1991; Neal, 2000).

\section{Diferenças}

Mas, ao contrário da passividade causada no público por esses produtos destinados ao entretenimento massivo, o produzido pelas utopias políticas e religiosas é proativo. Tais obras engajadas clamam pelo envolvimento das pessoas. Cabe perguntar, portanto, em que medida o imprint mental produzido no público pelo entretenimento se distingue do produzido pelas utopias políticas, pelas notícias e por outros discursos similares que visam conectar a audiência diretamente aos fatos correntes?
A primeira diferença é que a passividade provocada na audiência pelo entretenimento deriva de sua aparência fútil. Ela é a responsável por esta impressão de seu desinteresse político. A verdade, no entanto, é que os bens simbólicos da indústria do passatempo são um meio poderoso de educação e mobilização das massas, pois impactam o imaginário social de uma forma bem mais imperceptível que os produtos do jornalismo e da política. Se assim não fosse, haveria que se questionar por que os filmes de Hollywood foram amplamente utilizados pelos norte-americanos no período da II Guerra Mundial para administrar o humor coletivo de sua população (o front interno, conforme a prosa da época)? Por que eles serviram também de instrumento para conquistar a simpatia da opinião pública internacional aos Aliados (Koppes \& Black, 1990)? Por que há tanta preocupação com a estereotipia produzida pelas telenovelas e pelos filmes sobre as minorias raciais, religiosas, étnicas, de povos estrangeiros 
e das mulheres (Freire Filho et al., 2004; Said, 2007; Bhabha, 2005)? Da mesma forma, cabe perguntar sobre 0 papel que as revistas em quadrinhos norte-americanas têm na difusão dos valores do capitalismo entre as crianças (Dorfman $\&$ Mattelart, 1980). Ou por que a telenovela foi utilizada para fazer campanha contra as drogas, como foi o caso de 0 Clone, apresentada pela Rede Globo no período de outubro de 2001 a junho de 2002 ? $0 u$, ainda, por que as telenovelas foram utilizadas no Brasil também para difundir a pílula anticoncepcional e assim influenciar na queda da fertilidade das mulheres (Desidério, 2004; La Ferrara, 2008)? Todas estas fontes assumem a hipótese de que 0 entretenimento é fator grave que ajuda a moldar a cognição e, por decorrência, o comportamento das pessoas. Decorre desta constatação a inclusão da indústria cultural de um país na categoria de 'soft power' (Nye, 2005).

Ou seja, o imprint mental causado pela cultura popular no inconsciente social é poderoso, 0 que explica ainda 0 interesse dos nacionalistas, por exemplo, em bloquear de alguma maneira a influência cultural estrangeira. Cabe lembrar a respeito que, no passado, o Brasil era chamado de país oco (Lambert, 1969). As elites se voltavam à Europa, e suas mentes estavam povoadas por termos em francês, pelos autores europeus e por um imaginário distante dos motivos emanados das terras tropicais. Tal influência estrangeira acabaria sendo rotulada pejorativamente de imperialismo cultural (Ianni, 1976). Oliveira (1991) foi ao extremo de classificá-la como 'genocídio cultural'. Ainda em 1933, Raphael Lemkin, consultor jurídico da Liga das Nações, pronunciou-se de forma similar. Ele classificou de 'vandalismo' a destruição de certa cultura e de trabalhos de arte. Ele disse, em seu parecer sobre o genocídio, que

\begin{abstract}
"um ataque a uma coletividade pode também adotar a forma de destruição sistemática e organizada da arte e da herança cultural na qual 0 gênio especial e a realização da coletividade são revelados nos campos da ciência, artes e literatura. A contribuição de qualquer coletividade particular do mundo forma a riqueza de toda a humanidade, mesmo quando exibindo características singulares". ${ }^{3}$
\end{abstract}

Outros exemplos ainda de motivos à crítica que usualmente se faz ao poder da mídia são o conteúdo violento dos desenhos infantis (Fernandes, 2003) e 0 temor à influência de valores estrangeiros veiculados na televisão e noutros veículos vistos como capazes de alterar os padrões políticos, de moralidade e de religiosidade local (Kalathil \& Boas, 2003). A classificação indicativa de idade para a programação da televisão e do cinema mostra que o impacto deste tipo de programação é considerado seriamente (Freitag, In Chagas, 2006). ${ }^{4}$

Esta é a segunda diferença. 0 motivo soft do entretenimento se instala no inconsciente social 
Figura 7: Estátuas de Buda foram destruídas no Afeganistão, em 2001, pelos militantes islâmicos do Talibã
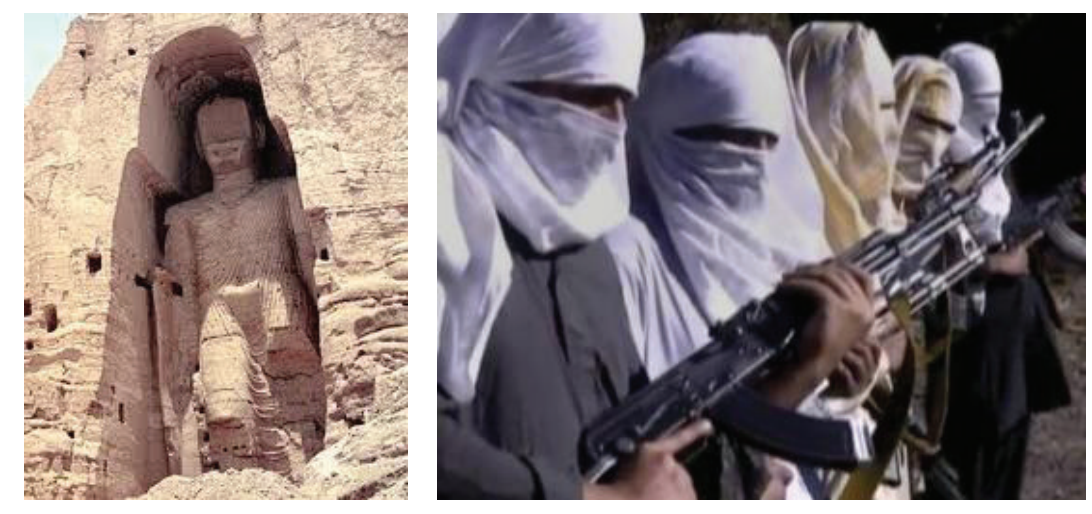

Fonte: clicar na imagem.

de maneira ardilosa. E, como mencionado, seus efeitos são sentidos e observados no comportamento do público em prazos geralmente mais longos do que os produzidos pelo conteúdo hard do discurso jornalístico e da política. Em boa medida, é assim também que age a educação informal, a que ocorre na família, nas igrejas, com os amigos, ou seja, a que surge da interação social com grupos de afinidade. Dessa forma, as influências recíprocas aparecem e através delas se difundem valores. 0 fato explica por que seus efeitos superam algumas vezes os produzidos nos espaços sociais dedicados à educação formal. Nesse sentido, Lady Gaga deve ser considerada uma educadora, já que seu poder de influência sobre a mente adolescente não deve ser desconsiderado. 0 seu show acabou proibido em Jacarta, em 2012, devido ao temor de sua influência sobre os jovens. As autoridades se opuseram ao conteúdo erotizado de seu show.
Na Arábia Saudita, ação similar proibiu o disco de Britney Spears que aparecia nua na capa.

\section{Sutileza}

0 Efeito Lady Gaga pode ser generalizado aos impactos comportamentais e morais produzidos no público, ou em parcela do mesmo, pelos personagens do showbis. Eles derivam não só do desempenho artístico, da expertise ou do vigor intelectual dos artistas, intérpretes, atores e autores, algo que pode ser medido e observado empiricamente, mas também devido à sutil aura midiática destes personagens, a que encanta, sobremaneira, os fãs em seu culto quase religioso destes atores.

No campo religioso acontece algo semelhante. É o que propõe Exodus 20,4: "Não farás para ti imagem esculpida, nem figura alguma do que há em cima no céu, nem em baixo na terra, nem nas águas debaixo da terra”. Em decorrência, 
inúmeras rebeliões iconoclastas têm tentado eliminar o fascínio que as imagens de objetos sacralizados exercem sobre os fiéis. Crença similar provocou a destruição das imagens de 53 metros de altura de Buda pelos talibãs na localidade de Barmiyan, no Afeganistão, em 2001.

0s grupos sunitas salafistas contemporâneos querem purificar o Islã de idolatrias e de influências nefastas, entre elas, o sufismo, uma vertente islâmica mística bastante popular e que age livre da influência teológica dos juristas tradicionais. Alguns hábitos sufistas, entre eles a veneração de santos e a visita a tumbas em cemitérios, são vistos pelos salafistas como superstições e, por isso, são considerados inaceitáveis. Por decorrência, é grande a tensão entre os dois grupos, em especial no Egito. Nesse país, os salafistas têm destruído inúmeros santuários sufistas. Com esses ataques, querem evitar a usual peregrinação que estimados 20 milhões de pessoas fazem a estes lugares de devoção.

\section{A força persuasiva do entretenimento deriva} do fato de que suas mensagens não são nunca percebidas como propaganda. Assim, com esta aparente inocência, as defesas psíquicas do público são debeladas. 0 simulacro permite, portanto, a difusão de mensagens sub-reptícias. Como exposto, a invisibilidade das sugestões utópicas oferecidas através dos bens simbólicos da indústria cultural é ainda maior que a sugerida no noticiário e noutros conteúdos hard. 0 jornalismo, por natureza, deseja ser um espelho do mundo. Este não é o caso dos filmes, das telenovelas, das obras de ficção e da música popular, por exemplo. A arte tem esta propriedade - a de liberar a imaginação dos grilhões dos fatos correntes, da moralidade vigente e dos usos e costumes existentes.

\section{A fuga}

Certamente, no curto prazo, o efeito cumulativo das mensagens que surgem das fantasias do entretenimento no inconsciente social é mais tênue que 0 gerado pelas hard news e por outros conteúdos similares. No entanto, o efeito de longo prazo que o bem simbólico é capaz de produzir na mente do público é politicamente relevante quando se leva em conta o fato de que boa parte do público prefere fugir do noticiário. Isso acontece porque 0 conteúdo hard demanda da audiência um grande desgaste de energia cognitiva em troca de [somente] um pequeno benefício afetivo (o prazer). 0 público escolhe se refugiar no entretenimento que assegura 0 oposto, ou seja, alto benefício afetivo com pequeno custo cognitivo. Prior (2005, p. 577-592) sugere que, apesar do aumento vertiginoso na oferta de informação, o conhecimento político médio do cidadão não se alterou. Este paradoxo é explicado com a evidência de que se tornou mais fácil às pessoas encontrar na infosfera seu conteúdo preferencial. Assim, quem gosta mais de notícias usufrui da abundância existente na oferta da informação política. Quem deseja evitar os hard 
news pode fazer o mesmo consumindo mais $\mathrm{e}$ mais entretenimento.

Os encontros do acaso são facilitados pela variedade de canais e veículos colocados à disposição da audiência. Deriva esta conclusão empírica a inferência de que o escapismo é possível, a despeito do fluxo incessante de informação que busca capturar o indivíduo e jogá-lo de imediato nas águas turvas da cidadania. Há que se salientar ainda que 0 entretenimento não ambiciona apresentar modelos fechados de mundos futuros. Sua ambição é discreta. Sua utopia é uma utopia do possível. Ao contrário das descrições apresentadas por ideologias e teologias, que visam a uma revolução existencial, 0 entretenimento estimula 0 desejo e 0 sonho a varejo, em dimensão micro, a que toca a dimensão vivencial e cotidiana das pessoas. Além do mais, 0 entretenimento atua principalmente na esfera restrita dos valores e das sensibilidades, algo que a música, por exemplo, produz (Ibid).

Este resultado explica a transformação do ritual religioso das igrejas protestantes nos Estados Unidos, em especial o pertencente às comunidades dos negros. Nesse caso, a pregação (hard) do evangelho passou a ser feito em um contexto intensamente diversional (soft), permeado pela catarse e pela música gospel (Neal, 2000, p.25). Revela-se aqui a fórmula de sucesso utilizado também pelo entretenimento: ele insere 0 conteúdo hard em um meio soft. Na educação esta tem sido a tarefa da didática, menos preocupada com o conteúdo e mais com a forma. E é ainda o que a mente realiza ao processar informações hard através do mecanismo soft da linguagem metafórica do inconsciente.

Cabe lembrar a respeito o eufemismo popular de 'adoçar a pílula' ou 'dourar a pílula'. 0 termo refere à estratégia de encobertar certa mensagem tornando seu impacto sutil à percepção do interlocutor. Ele surgiu a partir da experiência realizada pelo alquimista, filósofo e médico persa Abu Bakr Muhammad ibn Zakariyya al-Razi, ou simplesmente Rhazés, que viveu entre 865 e 923, de revestir remédios sólidos para que eles fossem mais facilmente ingeridos. Para tanto, utilizou sementes de sabor doce de uma planta cujo interior possuía uma substância que ficava viscosa quando entrava em contato com a água. Isso facilitava à pessoa engolir as pílulas. Depois, foi a vez do filósofo Abu Ali al-Husayn ibn Abd Allah ibn Sina, conhecido no Ocidente como Avicena, de utilizar folhas de ouro e prata para revestir os comprimidos. Assim, eles ficavam mais bonitos e atraentes ao olhar, muito embora isso não influísse no sabor da medicação. 'Dourar a pílula' tornou-se a partir daí um eufemismo para mascarar a realidade. Outras expressões populares similares são 'levar as pessoas no bico' e 'passar a conversa' em alguém.

Portanto, este tipo de discurso mitigado tem como objetivo abrandar o significado do que se diz. No campo político, por exemplo, ele serve para disfarçar a conquista do poder por algum ator 
social (Tajfel, 2010, p. 193). No campo musical, destaca-se a crítica que pregadores cristãos têm feito ao rock. Por exemplo, Jeff Godwin, em suas aparições, relata ao público sua trajetória de roqueiro e viciado em drogas. Para Godwin, este ritmo é satânico, pois está carregado de conotação sexual, divulga a promiscuidade e 0 uso de entorpecentes. Diz que o rock and roll e a perversão são a mesma coisa. A violência (Njaine et al, 2004) e o conteúdo erotizado da televisão brasileira têm sido também criticados por induzir as pessoas de forma subliminar a comportamentos antissociais (Freitas et al, 2006).

\section{Os efeitos}

Este tipo de estudo, os relacionados aos discursos da mídia e aos seus conteúdos, faz parte de uma já antiga tradição de scholarship, a que se interessou pelos efeitos da comunicação massiva na sociedade. 0 seu impacto na audiência, tema aqui destacado, é um entre vários desta área agora conhecida como 'crítica da mídia’. A comunicação intercultural se aliou a este esforço e trata agora de avaliar também se 0 discurso mitigado é fenômeno universal. Linguistas têm mostrado que ele varia de cultura a cultura. Não é o que usualmente acontece na China, mas é o padrão cultural estabelecido no Japão (Tannen, 1994). Ele é referido em inglês através da expressão gold plating (revestir em ouro) ou sugarcoat (envolver em açúcar).

A mesma expressão existe em inúmeras línguas, o que parece revelar sua função pragmática em inúmeros países e culturas do mundo. ${ }^{5}$ É uma maneira polida e delicada de informar as pessoas (estratégia retórica utilizada por médicos na comunicação de um diagnóstico, por exemplo), ou de dar ordens a subordinados (que acedem mais facilmente à demanda da autoridade desta forma).

Este discurso indireto, usual no entretenimento, facilita 0 enlace entre falantes e ouvintes. Nesse sentido, pode-se dizer que ele é manipulativo. Devido a este efeito que resulta da capacidade dos filmes, da música popular e de outros produtos simbólicos de esconder seu papel educativo, apresentando-se como algo casual e despretensioso, é que os valores do entretenimento acabaram influenciando de forma marcante todas as áreas criativas, até mesmo as que provêm de campos austeros, como é o caso da literatura, da política, da religião, do jornalismo, da arte e de outras áreas da produção intelectual (Gabler, 2000).

\section{Metáforas}

Como proposto, a metáfora é a linguagem do inconsciente. E, como afirmado, ela está een suikerlaagje voorzien, mooier voordoen, suikerlaagje; em francês: enrober de sucre ; em alemão: mit Zucker überziehen;

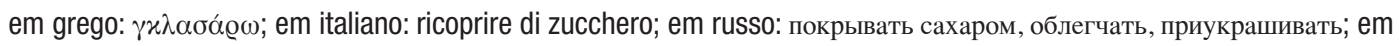
espanhol: confitar, garapiñar, dorar la píldora, endulzar; em sueco: överdra med socker, dragera, sockra, göra mer lättsmält; em chinês (simplificado): 加上糖衣, 使有吸引力; em chinês tradicional: 加上糖衣, 使有吸引力; em coreano: 당의를 입히다, 먹기 좋게 하다, 보기 좋게 꾸미다; em japonês: 糖衣をかける, 口当たりをよくする. (answers.com) 


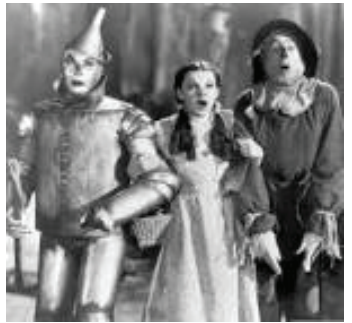

0 Mágico de $\mathrm{Oz}$

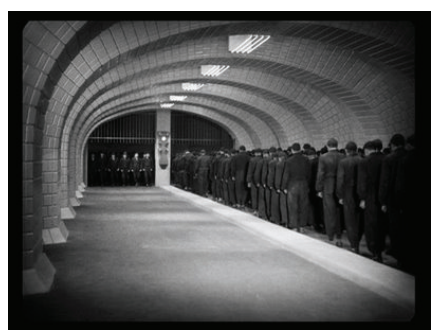

Metrópolis

Fonte: clicar na imagem.

presente também nas fantasias produzidas pela indústria cultural. É sempre mais fácil ao público processar sua vivência através de expedientes indiretos como esse. Vimos que a maneira com que certo conteúdo é divulgado é relevante à qualidade de seu processamento. No caso dos sonhos, burla-se através da metáfora a vigilância da consciência. 0 filósofo da linguagem Max Black (1962) propõe que ela age como 'um filtro'.

0 significado original de metáfora em grego é 'transferência'. Ou seja, através da analogia entre duas coisas distintas, se comunica algo. No exemplo referido, o medo às armas químicas, às centrais nucleares, à poluição ambiental e a outros males da civilização moderna é processado pela fantasia do Golem. A moral dessa história ensina que o ser humano deve dominar suas invenções, ao custo, às vezes, do arrependimento. Segundo a alegoria, isso é possível retirando da testa de seus artefatos a mágica letra ' $\mathrm{E}$ ' que lhes assegura o sopro da vida.
Lakoff \& Johnson (1980) dizem que a metáfora está presente em nossa linguagem, pensamentos e ações. E a maneira como pensamos, o que experimentamos e o que fazemos no dia a dia são objetos da metáfora. Algo profundo e invisível está escondido atrás de sua narrativa literal. $\mathrm{Na}$ arte, este expediente retórico é usual. Exemplos alegóricos adicionais são 0 Mágico de Oz, a Parábola da Caverna de Platão, o Último Unicórnio e o filme Metrópolis (Figura 8).

Portanto, a rota parece ser esta: certa emoção grave gerada no ambiente (o medo, por exemplo) é processada pelas imagens metafóricas usuais dos sonhos e da mitologia (a rebelião do Golem). Este simulacro é um disfarce. A fantasia, ao chegar à consciência, depois de um lento vagar através de discretas conexões simbólicas, alerta, por fim, os sentidos. A distopia (a autonomia das máquinas, no caso do Golem) é finalmente superada pela utopia (o anarcoprimitivismo), que se expressa sem subterfúgios, através de uma prosa prescritiva. 
Ou seja, as emoções fortes e distópicas, por serem perturbadoras, mergulham necessariamente no inconsciente profundo. Através da mediação da fantasia e de seus disfarces, seus graves efeitos afetivos são amenizados e amortecidos. É mais fácil elaborar, por exemplo, sobre o apocalipse através do Super-Homem e de suas aventuras do que através de um tratado teórico (e ansiogênico) sobre 0 'equilíbrio do poder'.

Yockey (2008) chama a atenção a este tipo de personagem que combate 0 crime. Nestas narrativas, destaca-se a preocupação que ele tem com seu próprio passado traumático. SuperHomem foi marcado pela destruição do planeta de sua infância. Ele resolve, então, proteger as pessoas das ameaças à sua sobrevivência. Young Bruce Wayne testemunhou o assassinato de seus pais. Depois, ele decide declarar guerra ao crime tornando-se Batman. 0 adolescente Peter Parker se transforma em Homem-Aranha após 0 assassinato de seu tio Ben por ladrões. É fácil perceber que a missão retificadora destes personagens do mundo da ficção e da fantasia é similar à de seres reais que se dispõem a consertar o mundo, mesmo ao custo do martírio (Fierke, 2013). As utopias políticas e religiosas, da mesma forma que os filmes do Super-Homem, de Batman e do Homem-Aranha, oferecem imaginação, escatologia, segurança, esperança, energia e excitação (Boshshart \& Hellmuller, 2009).

No jornalismo, a moral da história veiculada por uma notícia deriva da inferência do não dito, mas comunicado. Como as boas notícias são as más notícias (conteúdo distópico), 0 que subjaz no inconsciente social é a utopia (Wainberg, 2014). Ou seja, o interditado utópico é o seu viajante clandestino. Atrás do pessimismo, subjaz sempre o seu oposto, 0 otimismo. 0 processo de transformação simbólica de um estado de espírito noutro demanda conexões não triviais entre os motivos que representam o estado do mundo existente e os que representam 0 vislumbrado (imagem espelhada). No entretenimento, o cálculo afetivocognitivo exige conexões simbólicas menos complexas. 0 espetáculo serve de lubrificante social à sua mensagem sutil. 0s personagens da teledramaturgia, da literatura, da cinematografia e do showbis espelham, de forma metafórica, 0 que se quer e 0 que se almeja comunicar.

Quando os conteúdos comunicados são otimistas, eles ficam depositados no subconsciente. Por isso mesmo, eles permanecem em posição stand by para serem acessados rápida e facilmente. Dito de outra maneira: nem todo sonho e fantasia é distópico. As emoções geradas pelos produtos culturais despertam também sentimentos otimistas e pró-sociais, entre eles a solidariedade, o amor e a compaixão. Por consequência, por ser pró-social e positivo, o seu mergulho na subjetividade é tênue. É o caso, por exemplo, do Popeye. Este personagem se transformou em um relações-públicas não só do espinafre, mas também do vegetarianismo e de toda alimentação saudável. ${ }^{6}$ A mesma função é exercida por personagens clássicos da literatura e do folclore 


\section{Figura 9}

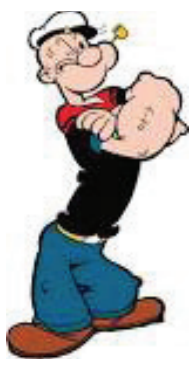

Popeye

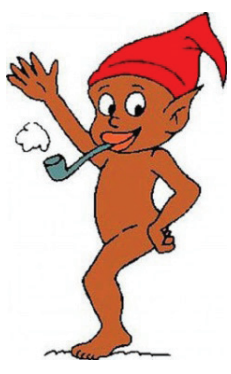

Saci Pererê nacional. Eles são acessados pelo público para exemplificar situações, atitudes, dilemas e valores. Basta lembrar, por exemplo, as figuras clássicas de Saci Pererê (Figura 9); Quincas Borba, de Machado de Assis, e Policarpo Quaresma, de Lima Barreto.

0 filósofo alemão Ernst Bloch diz que os rastros dos sonhos utópicos podem ser encontrados nos produtos culturais e nos usos e costumes do dia a dia das pessoas comuns. Elas percebem em seus cotidianos a incompletude da vida. Para Bloch, sempre existem possibilidades e alternativas. 0 que as ativa é a consciência antecipadora deste potencial. É necessário apontar uma perspectiva de futuro, algo que a mídia usualmente faz através de seus personagens, dramas e narrativas.

Os elementos utópicos presentes no cotidiano são sempre potenciais e coexistem com a realidade. Eles podem ser facilmente excitados através dos estímulos simbólicos existentes na arte. Na obra $O$ Princípio Esperança (Bloch, 2005-2006), a utopia é vista não como um sonho longínquo ou uma fantasia, mas como uma possibilidade que impede que as pessoas se resignem ao existente. Assim, os seres humanos devem se lançar ativamente naquilo que vai se tornando. Em todo presente, há um impulso e uma antecipação do que ainda não veio a ser. Pensar significa transpor. E se alguém sonha, não fica parado.

Há no contraste entre a utopia e o entretenimento um paradoxo. Os anseios utópicos, por definição, são inalcançáveis. É mais seguro afirmar, portanto, que o hiper-real de hoje é que poderá se tornar a realidade do amanhã. Deve-se perceber a distinção entre a pretensão de redenção existencial das ideologias e das teologias e o tratamento dos dilemas vivenciais realizados pelos programas de entretenimento. A 


\begin{abstract}
A fantasia
O sonho e o entretenimento

0 discurso mitigado
\end{abstract}
A autonomia das máquinas (-) 0 ser humano brinca de Deus 0 Golem (EMET/MET)

\begin{abstract}
A Distopia
0 medo à tecnologia e seus efeitos colaterais (tecnofobia) (-)
\end{abstract}

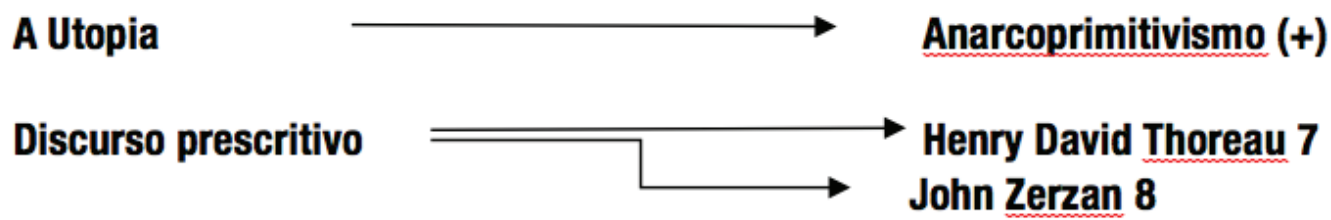

Figura 11: A alegoria utópica: 0 mergulho no subconsciente (+)

\section{A fantasia \\ 0 sonho e o entretenimento \\ 0 discurso mitigado}

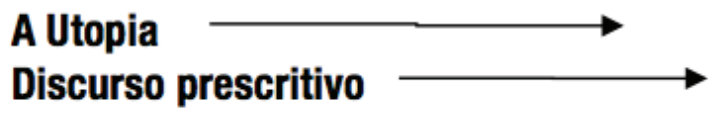

Espinafre é a força (+)

Somos o que comemos

Popeye

Vegetarianismo (+)

Anna Kingsford 9 teledramaturgia, a publicidade, a música popular e a cinematografia, por exemplo, ao se posicionarem mais próximas do cotidiano, despertam na audiência desejos realizáveis no curto prazo. 0 pragmatismo destes conteúdos é instrumento persuasivo mais eficiente que a derivação lógica exigida pelos tratados sociológicos e políticos. Para o público em geral, Madonna é mais acessível que Marx (Figura 12). A fala da cantora é mais inteligível e sua prédica mais emocional. 0 efeito persuasivo ocorre aqui também porque o conteúdo hard de sua prosa é disseminado através de um meio soft, sua performance teatral e musical.

Como dito anteriormente, o labor do discurso vivencial é feito no varejo, enquanto as narrativas existenciais contemplam sistemas complexos. 0 ideal revolucionário ambiciona salvar a humanidade toda, enquanto o produto cultural enfrenta dilemas triviais. Neste 


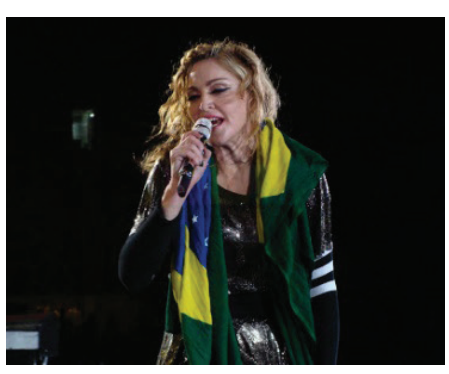

Madonna

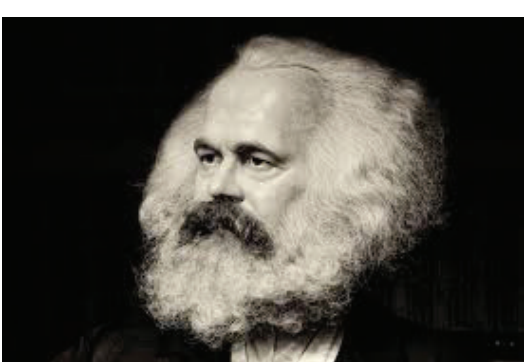

Marx

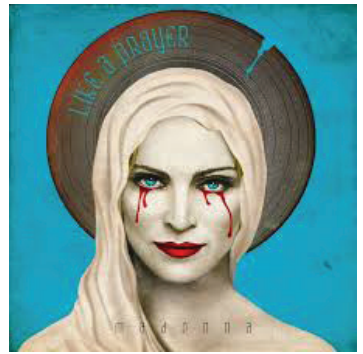

Madonna confronto, as modestas reformas do dia a dia sugeridas pelo entretenimento levam vantagem sobre a pretensão dos filósofos sociais. 0 bom senso do senso comum ensina que quem muito quer pouco consegue. É o que canta, por exemplo, a música Quem Muito Quer Nada Tem do grupo 'Tá na Mente'.

Por seus efeitos práticos e terapêuticos que servem de antídoto às profecias redentoras, o senso comum também recorda a mensagem de Maquiavel. Ele adverte as pessoas de que 0 bem se faz aos poucos. 0 labor humano não é heroico, ao contrário do que sugeriam as fantasias guerrilheiras do passado recente na América Latina e as prédicas salafistas de hoje no Oriente Médio. Este alerta também é difundido na cultura popular. É o caso, por exemplo, da música Pontes Indestrutíveis, interpretada pela banda Charlie Brown Jr.

\section{Os dilemas vivenciais}

Certamente, a resolução dos dilemas vivenciais implica sempre em angústia. Tais decisões envolvem escolhas entre valores distintos e contraditórios. Mas é exatamente a tensão existente entre essas rotas alternativas o fator que atrai a curiosidade do público aos produtos da ficção. As escolhas e seus valores elaboram sobre as encruzilhadas e as trilhas que os sujeitos podem escolher em suas vidas. Nesse sentido, as telenovelas e a cinematografia, entre outros produtos simbólicos, ao explorarem os dilemas vivenciais, tornam-se provedoras de pistas às audiências. Seu papel educativo é sutil, mas evidente. 0 s telespectadores sabem que $0 \mathrm{plot}$ do drama e que seus personagens não são reais. 0 dilema que eles enfrentam, no entanto, parece ser. Assim, o mundo hiper-real funciona como um laboratório de vivências no qual mergulham os 
produtores e os espectadores. Por decorrência, formula-se aqui 0 argumento de que, assim como a religião e a educação, o entretenimento também é política por outros meios. Ao dar conta dos dilemas vivenciais, os resultados de curto prazo das obras de ficção são mais palpáveis que os de longo prazo sugeridos pelas prédicas revolucionárias (Wainberg, 2013).

A emoção retira as massas de sua sonolência e enfado. A religião se vale do mistério (algo que ela tem em comum com a ficção científica). 0 jornalismo dissemina o medo. 0 esporte exorciza a agonia. 0 turismo oferece ao consumo a diferença. E a dramaturgia, como dito, explora os dilemas triviais do dia a dia.

A novela Laços de Família, apresentada pela Rede Globo em 209 capítulos entre 2000-2001, é exemplo disso. Trata-se de um estudo do papel do amor na sociedade. Entre os dilemas exorcizados na obra, está 0 amor proibido entre duas pessoas de idades diferentes e 0 amor altruísta, 0 que gera a vida ao custo da paixão perdida. Outro ainda é 0 custo pago por uma pessoa ao cultivar o amor platônico. Na verdade, essa narrativa faz uma tipologia do amor. Outras espécies de amores presentes na obra são 0 amor erótico, 0 amor verdadeiro, 0 amor lúdico, o amor afetuoso, o amor pragmático e 0 amor maníaco. Vários sentimentos acompanham os personagens envolvidos nas tramas: a culpa, a decepção, o desprezo, a dúvida, a frustração, a hipocrisia, a inveja, o mistério, a revelação, o pecado, o preconceito, a raiva, a surpresa e a traição. A moral da história é simples, mas significativa, pois reforça os bons sentimentos dos telespectadores. 0 amor gera a paz, enlaça as pessoas e produz a serenidade. Esta máxima geral deriva de outras menores e coadjuvantes. 0 amor é conversão. É pureza e é milagre. 0 amor é mais forte que a tentação. 0 amor vence a inequidade. 0 pecado não compensa. 0 amor é uma bênção. 0 amor é um ato altruísta compensador.

\section{Considerações Finais}

0 argumento proposto é de que os sonhos e os pesadelos despertos sobre a sociedade do futuro pelos conteúdos da indústria do passatempo ajudam a motivar as ações das pessoas no presente. Embora a influência do entretenimento seja sutil, seu impacto de longo prazo no clima de opinião pública e no comportamento dos indivíduos é relevante. Por isso mesmo, este fator tem sido levado em conta por agentes sociais envolvidos em campanhas persuasivas. A repercussão política da assertiva é evidente. 0 conteúdo lúdico funciona porque fura 0 bloqueio da crítica, 0 guardião da consciência. Seu disfarce na metáfora e no discurso mitigado é o mecanismo soft que lubrifica a difusão de conteúdos graves e sérios. Seu imprint mental é tênue, mas eficaz. Ele se acumula em camadas sobrepostas e, com o tempo, exerce sua influência nas preferências e na motivação política das pessoas. As utopias vivenciais que surgem são mais fortes que as existenciais. As telenovelas e os filmes elaboram sobre episódios da vida humana, sobre dilemas vivenciais pontuais. Assim, 
dourando a pílula, educam as massas sobre valores. As fantasias da hiper-realidade processam, por consequência, dilemas reais. E este parece ser seu poder mágico. A linguagem metafórica encanta devido a esta sua capacidade de dizer algo, mas comunicar outra coisa. Ela parece ser fútil, muito embora seu conteúdo verdadeiro seja relevante à vida das pessoas.

No estudo que fazem sobre os sonhos cotidianos das pessoas, Bain et al. (2013) reforçam este argumento. Eles mostram que o que mais sensibiliza a maior parte das pessoas não são os temas existenciais, mas os vivenciais. Não é a preocupação com a solução dos problemas sociais e o desenvolvimento econômico futuro da sociedade 0 que ativa 0 comportamento no presente. 0 que as motiva, de fato, é um desejo mais coloquial, o de combater a sensação de declínio social com a benevolência. É através da bondade, da condescendência e da boa vontade que as pessoas esperam poder construir laços comunitários com pessoas bem-intencionadas. Tal motivação é bem menos impactante que os gritos de guerra e os mantras revolucionários, mas é algo que a ficção ensina de forma discreta todos os dias através da literatura, da telenovela, dos filmes e da música popular.

\section{Referências}

AZIMOV, Isaac. Eu, Robô. Ediouro-Sinergia, 2004.

BAIN, Paul G.; HORNSEY, Matthew J.; BONGIORNO, Renata; KASHIMA, Yoshihisa; CRIMSTON, Daniel. 'Collective Futures. How Projections About the
Future of Society are Related to Actions and Attitudes Supporting Social Change.' Personality and Social Psychology Bulletin. Abril 2013, v.39, n.4, p. 523-539. In http://psp.sagepub.com/content/39/4/523.full BAUDRILLARD, Jean. Simulacros e Simulações. Lisboa: Relógio D’Agua. 1991.

BHABHA, Homi K. 0 local da cultura. UFMG, 2005.

BLACK, Max. Models and Metaphors. Studies in Language and philosophy. 1962.

BLOCH, Ernst. 0 Princípio Esperança. RJ: Eduerj. 2005/2006.

BOSHSHART, Louis, and Lea HELLMULLER.

'Pervasive entertainment, ubiquitous entertainment.' Communication Research Trends 28.2 (2009): 3+. Academic 0neFile. Web. 7 Apr. 2014.

BROCK, Timothy Brock \& LIVINGSTON, Stephen.

The psychology of entertainment media : blurring the lines between entertainment and persuasion. Lawrence Erlbaum Associates. Mahwah, NJ. 2004

DESIDÉRIO, Olábio Marcos Martins. Telenovela e Comportamento Social - a Questão das Drogas em 0 Clone. Dissertação de Mestrado. Universidade Federal de Goiás. 2004.

DORFMAN, Ariel \& MATTELART, Armand. Para Ler o Pato Donald: Comunicação de Massa e o Colonialismo. RJ: Paz e Terra, 1980

DYER, Richard. Only Entertainment. Londres/ Nova York: Routledge, 2002. In: http://isites.harvard. edu/fs/docs/icb.topic1069028.files/Dyer\%20on\%20 Entertainment.pdf

FERNANDES, Adriana Hoffmann. As mediações na produção de sentidos das crianças sobre os desenhos animados. Dissertação de Mestrado. PUCRio, 2003.

FIERKE, K.M. Political Self-Sacrifice. Cambridge University Press. 2013. 
FREIRE FILHO, João; HERSCHMANN, Micael \& PAIVA, Raquel. Estereótipos e representações midiáticas.

Compós. Dezembro, 2004.

FREITAG, Barbara. 'Psicologia do desenvolvimento moral: em busca de um ética discursiva na televisão brasileira.' In Chagas, Claudia Maria de Freitas; Romão, José Eduardo Elias \& Leal, Sayonara. Classificação Indicativa no Brasil: desafios e perspectivas.

Ministério da Justiça, 2006, p. 183-196.

GABLER, Neal. Life the Movie: How entertainment conquered reality. Vinage, 2000.

HEDGES, Chris. Empire of Illusion. The End of Literacy and the Triumph of Spetacle. Nation Books. 2009.

IANNI. 0. 0 imperialismo e a cultura. RJ: Vozes, 1976.

KALATHIL, Shanthi \& BOAS, Taylor C. Open networks, closed regimes. Carnegie Endowment for International Peace. 2003.

KOPPES, Clayton R. \& BLACK, Gregory D. Hollywood goes to war: How politics, profits and propaganda shaped World War II Movies. University of California Press, 1990.

LA FERRARA, Eliana; CHONG, Alberto \& Duryea. Soap Operas and Fertility: Evidence from Brazil. READ.

Working paper. n. 172, Março de 2008.

LAKOFF, George \& JOHSON, Mark. Metaphors We Live By. The University of Chicago Press. 1980.

LAMBERT, Jacques. Os Dois Brasis. SP: Cia Editora Nacional. 1969.

NJAINE, Kathie Njaine \& MINAYO, Maria Cecília de Souza. 'A violência na mídia como tema da área da saúde pública: revisão da literatura.' In Ciência \& Saúde Coletiva, 9(1):201-211, 2004.

NYE, Joseph. Soft Power. The means to success in World Politics. 2005.
OLIVEIRA, Ômar Souki. Genocídio Cultural. SP: Paulinas. 1991.

PRIOR, M. 'News vs. Entertainment: How Increasing Media Choice Widens Gaps in Political Knowledge and Turnout.' American Journal of Political Science, 49: 577-592. 2005.

SAID, Edward. Orientalismo - o Oriente como Invenção do Ocidente. Cia das Letras. 2007.

TAJFEL, Henri (ed). Social Identity and Intergroup Relations. Cambridge University Press. 2010.

TANNEN, Deborah. 'How to give orders like a man'. The New Yor Times Magazine, 28 de agosto de 1994.

TRACHTENBERG, J. Jewish Magic and Superstition. University of Pensylvania Press, 2012.

WAINBERG, Jacques A. '0 dilema do rebelde: persuasão ou sectarismo'. Revista Galáxia. SP. Online. № 26 , p. 34-47, Dez 2013. http://revistas.pucsp.br/index.php/ galaxia/article/viewFile/13493/13018 . 'Os títulos, as emoções e a utopia'.

Revista da Intercom. Primeiro semestre de 2015.

YOCKEY, Matt. 'Somewhere in Time: Utopia and the Return of Superman.' The Velvet Light Trap. 61 (2008) 26-37. 


\begin{tabular}{|c|c|}
\hline $\begin{array}{l}\text { Entertainment, utopia } \\
\text { and the mitigated speech }\end{array}$ & $\begin{array}{l}\text { Entretenimiento, utopia } \\
\text { y el discurso mitigado }\end{array}$ \\
\hline $\begin{array}{l}\text { Abstract } \\
\text { This study elaborates on the role of entertainment in } \\
\text { the consolidation of a utopian imaginary. It examines } \\
\text { the role of metaphoric discourses in mythic allegories } \\
\text { and other symbolic contents as those produced by } \\
\text { films and soap operas. It also distinguishes between } \\
\text { existential and experiential utopias and shows the } \\
\text { relevance of subtle messages in the consolidation of } \\
\text { political motivation of the people. } \\
\text { Keywords } \\
\text { Utopia. Speech. Entertainment. Metaphor. Persuasion. }\end{array}$ & $\begin{array}{l}\text { Resumen } \\
\text { Este estudio teórico profundiza en el papel de } \\
\text { entretenimiento en la consolidacion de uma fantasia } \\
\text { utópica. Examina el papel del discurso metafórico } \\
\text { utilizado em las alegorias míticas y otros bienes } \\
\text { simbólicos como los produzidos por la industria del cine } \\
\text { y las telenovelas. Distingue entre las utopias existenciales } \\
\text { y experienciales y muestra la relevancia de la sutileza } \\
\text { de las mensajens de la industria del pasa tiempo em la } \\
\text { consolidación de las motivaciones politicas. } \\
\text { Palabras clave } \\
\text { Utopía. Discurso. Entretenimiento. Metáfora. Perusasión. }\end{array}$ \\
\hline
\end{tabular}




\section{Expediente}

A revista E-Compós é a publicação científica em formato eletrônico da Associação Nacional dos Programas de Pós-Graduação em Comunicação (Compós). Lançada em 2004, tem como principal finalidade difundir a produção acadêmica de pesquisadores da área de Comunicação, inseridos em instituições do Brasil e do exterior.

\section{E-COMPÓS I www.e-compos.org.br I E-ISSN 1808-2599}

Revista da Associação Nacional dos Programas de Pós-Graduação em Comunicação.

Brasília, v.18, n.1, jan./abri.. 2015.

A identificação das edições, a partir de 2008, passa a ser volume anual com três números.

\section{CONSELHO EDITORIAL}

Alexandre Rocha da Silva, Universidade Federal do Rio Grande do Sul, Brasil Alexandre Farbiarz, Universidade Federal Fluminense, Brasil Ana Carolina Damboriarena Escosteguy, Pontifícia Universidade Católica do Rio Grande do Sul, Brasil

Ana Carolina Rocha Pessôa Temer, Universidade Federal de Goiás, Brasil Ana Regina Barros Rego Leal, Universidade Federal do Piauí, Brasil André Luiz Martins Lemos, Universidade Federal da Bahia, Brasil Andrea França, Pontifícia Universidade Católica do Rio de Janeiro, Brasil Antonio Carlos Hohlfeldt, Pontifícia Universidade Católica do Rio Grande do Sul, Brasil

Arthur Ituassu, Pontifícia Universidade Católica do Rio de Janeiro, Brasil Álvaro Larangeira, Universidade Tuiuti do Paraná, Brasil Ângela Freire Prysthon, Universidade Federal de Pernambuco, Brasil César Geraldo Guimarães, Universidade Federal de Minas Gerais, Brasil Cláudio Novaes Pinto Coelho, Faculdade Cásper Líbero, Brasil Daisi Irmgard Vogel, Universidade Federal de Santa Catarina, Brasil Daniela Zanetti, Universidade Federal do Espírito Santo, Brasil Denize Correa Araujo, Universidade Tuiuti do Paraná, Brasil Eduardo Antonio de Jesus, Pontifícia Universidade Católica de Minas Gerais, Brasil

Eduardo Vicente, Universidade de São Paulo, Brasil

Elizabeth Moraes Gonçalves, Universidade Metodista de São Paulo, Brasil Erick Felinto de Oliveira, Universidade do Estado do Rio de Janeiro, Brasil Francisco Elinaldo Teixeira, Universidade Estadual de Campinas, Brasil Francisco Paulo Jamil Almeida Marques, Universidade Federal do Ceará, Brasil Gabriela Reinaldo, Universidade Federal do Ceará, Brasil Gisela Grangeiro da Silva Castro, Escola Superior de Propaganda e Marketing, Brasil

Goiamérico Felício Carneiro Santos, Universidade Federal de Goiás, Brasil Gustavo Daudt Fischer, Unisinos, Brasil

Herom Vargas, Universidade Municipal de São Caetano do Sul, Brasil
Itania Maria Mota Gomes, Universidade Federal da Bahia, Brasil Janice Caiafa, Universidade Federal do Rio de Janeiro, Brasil Jiani Adriana Bonin, Universidade do Vale do Rio dos Sinos, Brasil José Afonso da Silva Junior, Universidade Federal de Pernambuco, Brasil José Luiz Aidar Prado, Pontifícia Universidade Católica de São Paulo, Brasil Kati Caetano, Universidade Tuiuti do Paraná, Brasil

Lilian Cristina Monteiro França, Universidade Federal de Sergipe, Brasil Liziane Soares Guazina, Universidade de Brasília, Brasil Luíza Mônica Assis da Silva, Universidade de Caxias do Sul, Brasil Luciana Miranda Costa, Universidade Federal do Pará, Brasil Malena Segura Contrera, Universidade Paulista, Brasil Marcel Vieira Barreto Silva, Universidade Federal da Paraíba, Brasil Maria Ogécia Drigo, Universidade de Sorocaba, Brasil Maria Ataide Malcher, Universidade Federal do Pará, Brasil Maria Clotilde Perez Rodrigues, Universidade de São Paulo, Brasil Maria das Graças Pinto Coelho, Universidade Federal do Rio Grande do Norte, Brasil

Mauricio Ribeiro da Silva, Universidade Paulista, Brasil

Mauro de Souza Ventura, Universidade Estadual Paulista, Brasil Márcio Souza Gonçalves, Universidade do Estado do Rio de Janeiro, Brasil Micael Maiolino Herschmann, Universidade Federal do Rio de Janeiro, Brasil Mirna Feitoza Pereira, Universidade Federal do Amazonas, Brasil Nísia Martins Rosario, Universidade Federal do Rio Grande do Sul, Brasil Potiguara Mendes Silveira Jr, Universidade Federal de Juiz de Fora, Brasil Regiane Ribeiro, Universidade Federal do Paraná, Brasil Rogério Ferraraz, Universidade Anhembi Morumbi, Brasil Rose Melo Rocha, Escola Superior de Propaganda e Marketing, Brasil Rozinaldo Antonio Miani, Universidade Estadual de Londrina, Brasil Sérgio Luiz Gadini, Universidade Estadual de Ponta Grossa, Brasil Simone Maria Andrade Pereira de Sá, Universidade Federal Fluminense, Brasil Veneza Mayora Ronsini, Universidade Federal de Santa Maria, Brasil Walmir Albuquerque Barbosa, Universidade Federal do Amazonas, Brasil

\section{COMISSÃO EDITORIAL}

\section{Cristiane Freitas Gutfreind}

Pontifícia Universidade Católica do Rio Grande do Sul, Brasil

Irene Machado

Universidade de São Paulo, Brasil

Jorge Cardoso Filho

Universidade Federal do Reconcavo da Bahia, Brasil

Universidade Federal da Bahia, Brasil

$$
\begin{aligned}
& \text { REVISÃo DE TEXTOS I Press Revisão } \\
& \text { SECRETÁRIA EXECUTIVA I Helena Stigger } \\
& \text { EDITORAÇÃO ELETRÔNICA I Roka Estúdio }
\end{aligned}
$$

COMPÓS I www.compos.org.br

Associação Nacional dos Programas de Pós-Graduação em Comunicação

Presidente

Eduardo Morettin

Universidade de São Paulo, Brasil

eduardomorettin@usp.br

Vice-presidente

Inês Vitorino

Universidade Federal do Ceará, Brasil

ines@ufc.br

Secretária-Geral

Gislene da Silva

Universidade Federal de Santa Catarina, Brasil gislenedasilva@gmail.com 